\title{
Ameliyathanede Deri Hazırlığı Uygulamalarının İncelenmesi
}

\section{Investigation of Skin Preparation Practices in Operating Room}

\author{
Aliye OKGÜN ALCAN $^{1}{ }^{(D)}$, Kevser KARACABAY ${ }^{2} \mathbb{D}^{\mathbb{D}}$, Ayşegül SAVCI $^{2}$ \\ 1 İzmir Bakırçay Üniversitesi Sağlık Bilimleri Fakültesi Hemşirelik Bölümü, IZMiR \\ 2 Kütahya Sağık Bilimleri Üniversitesi Sağlık Bilimleri Fakültesi Hemşirelik Bölümü, KÜTAHYA
}

Öz.

Amaç: Bu çalışmanın amacı, ameliyathane hemşirelerinin deri hazırlığında kullandıkları aseptik teknik uygulamalarının incelenmesidir.

Materyal ve Metod: Tanımlayıcı tipte olan bu çalışmanın verileri Mart-Haziran 2019 tarihleri arasında araştırmacılar tarafından oluşturulan veri toplama formu ile internet üzerinden toplanmıştır. Çalışmanın örneklemini, çalışmaya katılmayı gönüllü olarak kabul eden, internet kullanabilen 154 ameliyathane hemşiresi oluşturmuştur. Verilerin analizinde ortalama, standart sapma, sayı ve yüzde kullanılmıştır.

Bulgular: Bu çalıșmada hemşirelerin sadece \%30,5 (n:47)'i çalıștıkları kurumda hastalara ameliyat öncesi rutin olarak duş/banyo yaptırıldığını belirtmiştir. Hemşirelerin \%63,6 (n:98)'sı ameliyat bölgesindeki tüylerin rutin olarak temizlendiğini ve \%60 (n:111)'ı tüy temizliğinin elektrikli tıraş makinesi ile yapıldığını belirtmişlerdir. Hemşirelerin \%69,8 (n:125)'i deri antisepsisinde povidon iyodin kullanıldı̆ı̆ın ifade etmişlerdir. Hemşirelerin \%69,5 (n:107)'i deri antisepsisinde kullanılan antiseptik solüsyonun hastanın altında birikmesini önlemek için hastanın her iki tarafına kompres yerleştirdiklerini belirtmişlerdir.

Sonuç: Sonuç olarak, bu çalışmada deri antisepsisinin uygun antiseptik solüsyon ile yeterli alanda, yeterli sürede ve uygun teknik ile yapııdığı belirlenmiștir. Ancak banyo/duşun rutin uygulanma oranının düşük olması, tüy temizliğinin gerekli olup olmadığı düşünülmeksizin çoğunlukla rutin yapılması ve tıraş bıçağının kullanılması nedeniyle ameliyathane hemşirelerinin cerrahi alan enfeksiyonlarını önlemeye yönelik bilgilerinin güncellenmesi önerilmektedir.

Anahtar Kelimeler: Ameliyathane hemşireliği, Deri hazırlığı, Asepsi

\section{Abstract}

Background: The aim of this study was to investigate the aseptic technique used in the preparation of skin by operating room nurses.

Materials and Methods: The data of this descriptive study was collected from the internet between March-June 2019 with the data collection form created by the researchers. The sample of the study consisted of 154 operating room nurses who voluntarily agreed to participate in the study and able to use internet. Mean, standard deviation, number and percentage were used for data analysis.

Results: In this study, only $30.5 \%$ (n:47) of the nurses stated that patients were routinely showered/bathed before surgery in the institution they work. Of the nurses, $63.6 \%$ (n:98) reported that hairs at the operation site were routinely removed and $60 \%$ (n:111) reported that hair removal was performed with a clipper. $69.8 \%$ (n:125) of the nurses stated that povidone iodine was used in skin antisepsis. 69.5\% (n:107) of the nurses stated that they placed compresses on both sides of the patient to prevent accumulation of the antiseptic solution used in skin antisepsis.

Conclusions: In conclusion, it was determined in this study that skin antisepsis was performed with appropriate antiseptic solution in a sufficient area, in a sufficient time and with appropriate technique. However, it is recommended to update the knowledge of the operating room nurses to prevent surgical site infections due to the low rate of routine application of the bath / shower, making the routine mostly regardless of whether hair removal is required or not, and using the razor blade.

Key words: Operating room nursing, Skin preperation, Asepsis

\section{Sorumlu Yazar I Corresponding Author}

Aliye OKGÜN ALCAN

İzmir Bakırçay Üniversitesi Gazi Mustafa Kemal Mahallesi Kaynaklar Caddesi Seyrek Menemen- 35665 IZMiR

Tel: 0(232) 4930000 Dahili: 1242 Faks: 0(232) 8447122

e-mail: aliye.alcan@bakircay.edu.tr, aliyeokgun@gmail.com

Geliş tarihi / Received: 27.09.2019

Kabul tarihi / Accepted: 12.03.2020

DOI: 10.35440/hutfd.626161 


\section{Giriş}

Cerrahi alan enfeksiyonları (CAE) dünya genelinde hasta güvenliğini tehdit eden, sık gelişen, önlenebilir olaylardır. Amerikan Hastalıkları Kontrol ve Önleme Merkezi (Centers for Disease Control and Prevention-CDC)'ne göre CAE; cerrahi girişimi takiben 30 ya da 90 gün içinde gelişebilen, ameliyat bölgesinde gözlenen enfeksiyonlar olarak tanımlamıştır (1). Sağlık hizmetleri ile ilişkili enfeksiyonların \%20'sini CAE'lerin oluşturduğu ve cerrahi girişim uygulanan hastaların en az \%5'inde CAE gelişmekte olduğu belirtilmiştir (2). Bunun yanı sıra CAE ile ilişkili mortalite oranın ise \%2-11 arasında olduğu bildirilmiştir $(3,4)$. Bu enfeksiyonların hastaların hastanede kalış süresini ve dolayısıyla da maliyeti arttırdığı belirtilmektedir (3). CAE gelişmesinde neden olan faktörler arasında yaşı ı ve kronik hastalığı olan bireylere uygulanan cerrahi girişim sayısında ve prostetik uygulamalarda artışın olduğu düşünülmektedir. Bunun yanı sıra, uygunsuz antibiyotik kullanımı sonucu antimikrobiyal ajanlara dirençli mikroorganizmaların artması, cerrahi teknik ve asepsi kurallarına yetersiz uyum diğer faktörler arasında sayılabilir $(3,5)$.

CAE'nın önlenmesinde ve kontrolünde en önemli girişimlerden birisi ameliyathanelerde kanit temelli aseptik kurallara uyulmasıdır (6-8). Bu amaçla uygulanan girişimlerden biri de deri hazırlığıdır. Ameliyat öncesi deri hazırığının amacl; ameliyat bölgesinin geçici ve kalıcı mikroorganizmalardan ve kirlerden arındırıması, kalıcı floranın azaltıması, temizleme işleminde deride irritasyon oluşturulmaması ve mikroorganizmaların üremesinin bir süre için azaltılmasıdır $(7,8)$. Çünkü cerrahi girişimle dermiste bulunan kalıcı mikroorganizmalar derin dokulara yerleşebilir ve cerrahi alan enfeksiyonlarına sebep olabilirler. Ameliyat öncesi duş/banyo yaptıııması, tüy temizliğinin sağlanması ve ameliyat masasında derinin aseptik solüsyonlarla temizliği deri hazırlığının basamakları olup, uygulanması ameliyathane hemşirelerinin görev ve sorumlulukları arasında yer almaktadır (7). Tüm bu uygulamalarla ilgili güncel kanıtlar olsa da, geleneksel yaklaşımlar hala uygulanmaya devam etmektedir (9). Kanıta dayalı uygulamalar ile CAE'nın yaklaşık yarısının önlenebileceği belirtilmektedir (1) Ancak sağlık çalışanlarının bilgi düzeyi, motivasyon durumu ve yeteneklerine bağlı olarak hastaların sadece yarısının güncel bilimsel kanıtlar doğrultusunda önerilen tıbbi bakımı alabildikleri bildirilmektedir (9). Bu nedenle ameliyathane hemşirelerinin cilt hazırlığı uygulamalarında kanıt temelli yaklaşımları benimsemesi ve uygulaması son derece önemlidir. Ülkemizde ameliyathane hemşirelerinin CAE'nı önlemek için güncel, kanıt temelli aseptik teknik uygulamalarını inceleyen ulusal bir çalışmaya rastlanmamıştır. Bu nedenle bu çalışma cerrahi alan enfeksiyonlarının önlenmesinde ameliyathane hemşirelerinin aseptik teknik uygulamalarının incelenmesi amacıyla yürütülmüştür.

\section{Materyal ve Metod}

Tanımlayıcı tipte olan bu çalışmanın verileri 22 Mart - 22 Haziran 2019 tarihleri arasında online anket sistemi kullanılarak toplanmıştır. Çalışmanın evrenini sosyal paylaşım sitelerinde "ameliyathane hemşireliği" gruplarına dahil olan hemşireler oluşturmuştur. Çalışmanın örneklemini araştırmanın yapıldığı tarihlerde aktif olarak ameliyathane hemşireliği yapan, internet kullanabilen, araştırmaya katımayı gönüllü olarak kabul eden 154 ameliyathane hemşiresi oluşturmuştur. Çalışmanın verileri araştırmacılar tarafından ilgili literatür doğrultusunda oluşturulan veri toplama formu ile internet üzerinden toplanmıştır. Bu form, hemşirelerin sosyo-demografik bilgilerini ve CAE'nın önlenmesine yönelik güncel, kanıt temelli önerileri uygulama durumlarını içeren 22 sorudan oluşmaktadır. Veri toplama formu 22 Mart 2019 tarihinde "http://www.surveey.com/SurveyStart.aspx?lang=1\&surv=d7b01a664862 4038821b76ab2182a087" internet adresi ile elektronik ortamda yayımlanmışır. Sosyal paylaşım siteleri üzerindeki gruplardan ameliyathane hemşirelerine çalışmanın amacı ve bağlantısını içeren bir davet mektubu gönderilmiştir. Çaışmaya katılımı artırmak amacıyla ilk davet mektubu gönderildikten iki hafta sonra hemşirelere hatılatma mesajı gönderilmiştir. Bir katıımcının tek anket doldurmasını sağlamak için IP denetlemesi sağlanmıştır. Veri toplama formunun doldurulması hemşirelerin yaklaşık 5-7 dakika zamanlarını almıştır. Çevrimiçi olarak doldurulan veri toplama formları araştırmacılar tarafından günlük olarak yedeklenmiştir. Çalışmadan elde edilen verilerin analizi, Statistical Package for the Social Sciences (SPSS) 20.0 programında yapılmışıtır. Verilerin değerlendirilmesinde sayı ve yüzde dağılımları kullanılmıştır. Sürekli verilerin normal dağılım gösterip göstermediğini belirlemek için Shapiro Wilk testi kullanılarak anlamlılık düzeyi $p<0.05$ düzeyinde olan değişkenlerin normal dağılım göstermediği yorumu yapıımıştır. Çalışmanın yürütülebilmesi için Kütahya Sağılı Bilimleri Üniversitesi Girişimsel Olmayan Klinik Araştırmalar Etik Kurulu'ndan yazılı izin alınmıştır (19.03.2019 tarih, 2019/04 nolu karar). Çalışmanın amacı ve yöntemine ilişkin bilgilere veri toplama formunun giriş kısmında yer verilmiştir. Bu bilgiler doğrultusunda soru formunun doldurulması, çalışmaya katılım için onay olarak kabul edilmiştir.

\section{Bulgular}

Hemşirelerin sosyo-demografik özellikleri Tablo 1'de görülmektedir. Hemşirelerin yaş ortalaması 33,1 $\pm 7,4$ (min:20, maks:51) yaş olarak belirlenmiştir. Hemşirelerin meslekte çalışma süre medyanı 10 (min:1, maks:32) yıl, ameliyathanede çalışma süre medyanı ise 7 (min:1, maks:32) yıl olarak saptanmışıı.

Bu çalışmada hemşirelerin \%76,0'sı (n:117) çalıştıkları kurumda CAE'nin önlenmesine yönelik yazılı protokol bulunduğunu; \%3,2'si (n:5) böyle bir protokol bulunmadığını; 
$\% 20,8$ 'i (n:32) ise protokol bulunup bulunmadığını bilmediklerini belirtmişlerdir. Araştırma kapsamına alınan ameliyathane hemşirelerinin deri hazırlığında kullandıkları aseptik teknik uygulamalarına göre dağılımı Tablo 2'de verilmiştir.

Tablo 1. Hemşirelerin Sosyo-demografik Özelliklerine Göre Dağlımları (N:154)

\begin{tabular}{|c|c|c|}
\hline Sosyo-Demografik Özellikler & Sayı (n) & Yüzde(\%) \\
\hline \multicolumn{3}{|l|}{ Cinsiyet } \\
\hline Erkek & 25 & 16,2 \\
\hline Kadın & 129 & 83,8 \\
\hline \multicolumn{3}{|l|}{ Yaşadığı Bölge } \\
\hline Doğu Anadolu & 1 & 0,6 \\
\hline Güneydoğu Anadolu & 5 & 3,2 \\
\hline Akdeniz & 11 & 7,1 \\
\hline İç Anadolu & 20 & 13,0 \\
\hline Karadeniz & 22 & 14,3 \\
\hline Ege & 44 & 28,6 \\
\hline Marmara & 51 & 33,1 \\
\hline \multicolumn{3}{|l|}{ Eğitim Durumu } \\
\hline Sağlık meslek lisesi & 14 & 9,1 \\
\hline Ön lisans & 24 & 15,6 \\
\hline Lisans & 87 & 56,5 \\
\hline Lisansüstü & 29 & 18,8 \\
\hline \multicolumn{3}{|l|}{ Çalıştığı Hastanenin Türü } \\
\hline Özel & 38 & 24,7 \\
\hline Üniversite & 41 & 26,6 \\
\hline Devlet & 75 & 48,7 \\
\hline \multicolumn{3}{|l|}{ Çalıştığı Ameliyathane* } \\
\hline Çocuk cerrahisi & 13 & 4,0 \\
\hline Göğüs cerrahisi & 14 & 4,3 \\
\hline Ortopedi & 23 & 7,1 \\
\hline Plastik ve rekonstrüktif cerrahi & 23 & 7,1 \\
\hline Üroloji & 23 & 7,1 \\
\hline Beyin ve sinir cerrahisi & 26 & 8,1 \\
\hline Kadın hastalıkları ve doğum & 28 & 8,7 \\
\hline Kalp damar cerrahisi & 30 & 9,3 \\
\hline Kulak burun boğaz & 30 & 9,3 \\
\hline Merkezi ameliyathane & 55 & 17,1 \\
\hline Genel cerrahi & 57 & 17,7 \\
\hline \multicolumn{3}{|c|}{ Ameliyathane hemşireliği sertifikası } \\
\hline Olan & 64 & 41,6 \\
\hline Olmayan & 90 & 58,4 \\
\hline \multicolumn{3}{|c|}{ Son 5 yıl içinde CAE önlenmesine yönelik eğitim } \\
\hline Almayan & 26 & 16,9 \\
\hline Alan & 128 & 83,1 \\
\hline
\end{tabular}

Bu çalışmada ameliyathane hemşirelerinin \%7,1'i (n:11) deri antisepsisi uygularken muayene eldiveni; \%92,9'u (n:143) steril eldiven kullandıklarını belirtmişlerdir. Hemşirelerin \%96,1'i (n:148) deri antisepsisini insizyon alanından dışarıya doğru yaptıklarıı belirtmiştir. Bunun yanında hemşirelerin deri antisepsisini \%2,6'sı (n:4) rastgele hareketlerle; \%1,3'ü (n:2) ise dışarıdan insizyon alanına doğru yaptığını ifade etmiştir.

Araştırma kapsamına alınan hemşireler deri antisepsisini ortalama 4,1 2,1 (min:1, maks:15) dakika ve insizyon alanında ortalama 21,6 $\pm 12,2$ (min:2, maks:60) cm uzaktaki mesafeye kadar uyguladıklarını belirtmişlerdir. Hemşirelerin \%42,2'si (n:65) deri antisepsisinden sonra hasta örtülmeden önce antiseptiğin kurumasını beklediklerini belirtmişlerdir.
Tablo 2. Hemşirelerinin Deri Hazırlığında Kullandıkları Aseptik

Teknik Uygulamalarına Göre Dağılımı (N:154)

\begin{tabular}{|c|c|c|}
\hline Deri Hazırlığında Kullanılan Aseptik Teknik Uygulamaları & Sayı (n) & Yüzde (\%) \\
\hline \multicolumn{3}{|l|}{ Ameliyat öncesi rutin duş/banyo } \\
\hline Yapılan & 47 & 30,5 \\
\hline Yapılmayan & 61 & 39,6 \\
\hline Bilmeyen & 46 & 29,9 \\
\hline \multicolumn{3}{|l|}{ Ameliyat öncesi duş/banyoda kullanılan ajan* } \\
\hline Povidon iyot & 7 & 14,6 \\
\hline Sabun/şampuan & 20 & 41,7 \\
\hline Klorheksidin glukonat & 21 & 43,8 \\
\hline \multicolumn{3}{|l|}{ Ameliyat bölgesindeki tüy temizliği } \\
\hline Rutin olarak yapılan & 98 & 63,6 \\
\hline Zorunlu olmadıkça yapılmayan & 56 & 36,4 \\
\hline \multicolumn{3}{|l|}{ Tüy temizliğinin yapıldığı alet ${ }^{*}$} \\
\hline Tüy dökücü krem & 3 & 1,6 \\
\hline Tıraş bıçağı/jilet & 71 & 38,4 \\
\hline Elektrikli tıraş makinesi (klipper) & 111 & 60,0 \\
\hline \multicolumn{3}{|l|}{ Tüy temizliğini yapan kişi ${ }^{\star}$} \\
\hline Ameliyathane teknikeri & 1 & 0,4 \\
\hline Berber & 2 & 0,8 \\
\hline Yoğun bakım hemşiresi & 3 & 1,3 \\
\hline Servis hemşiresi & 14 & 5,9 \\
\hline Ameliyathane hemşiresi & 17 & 7,2 \\
\hline Hekim & 37 & 15,6 \\
\hline Hasta/hasta yakını & 47 & 19,8 \\
\hline Yardımcı personel & 116 & 48,9 \\
\hline \multicolumn{3}{|l|}{ Tüy temizliğinin yapıldığı yer* } \\
\hline Yoğun bakım ünitesinde & 7 & 3,1 \\
\hline Ameliyathanede ameliyat salonu dışında özel bir odada & 7 & 3,1 \\
\hline Hasta evinde yapıyor & 41 & 18,1 \\
\hline Serviste & 74 & 32,7 \\
\hline Ameliyat salonunda & 97 & 42,9 \\
\hline \multicolumn{3}{|l|}{ Tüy temizliğinin yapılma zamanı } \\
\hline Hastaneye yatıştan önce & 5 & 3,2 \\
\hline Ameliyattan önceki gece & 42 & 27,3 \\
\hline Ameliyat sabahı & 21 & 13,6 \\
\hline Ameliyattan hemen önce & 86 & 55,8 \\
\hline \multicolumn{3}{|l|}{ Deri antisepsisinde kullanılan solüsyon } \\
\hline Alkol ve klorheksidin glukonat kombinasyonu & 2 & 1,1 \\
\hline Alkol & 3 & 1,7 \\
\hline Povidon iyodin ve alkol kombinasyonu & 11 & 6,1 \\
\hline Klorheksidin glukonat & 38 & 21,2 \\
\hline Povidon iyodin & 125 & 69,8 \\
\hline \multicolumn{3}{|l|}{$\begin{array}{l}\text { Deri antisepsisinde kullanılan solüsyonun hastanın altında } \\
\text { birikmesini önlemek için alınan önlemler }\end{array}$} \\
\hline Önlem almayan & 12 & 7,8 \\
\hline Antisepsi sonrası kompresle kurulamak & 2 & 1,3 \\
\hline Antiseptik solüsyonu az dökmek & 15 & 9,7 \\
\hline Hastanın altına örtü yerleştirmek & 18 & 11,7 \\
\hline Hastanın her iki tarafına kompres yerleştirmek & 107 & 69,5 \\
\hline \multicolumn{3}{|l|}{ Ameliyat bölgesinde steril drape kullanma } \\
\hline Vaka türüne göre karar veren & 39 & 25,3 \\
\hline Kullanan & 80 & 51,9 \\
\hline Kullanmayan & 35 & 22,7 \\
\hline
\end{tabular}

*Birden fazla yanıt verilmiştir.

\section{Tartışma}

CAE gelişimine neden olan en önemli faktörlerden bir tanesini hastanın kendi florası olduğu bilinmektedir $(10,11)$. Bu nedenle CAE'nin önlenmesinde deri hazırlığı önem taşımaktadır (12). Cerrahi hastalarının deri hazırlığının sağlanması ve sürdürülmesinde ameliyathane hemşirelerine önemli sorumluluklar düşmektedir $(7,10)$. Ameliyat öncesi deri hazırlığl; ameliyat öncesi duş/banyo, tüy temizliği ve deri antisepsisini kapsamaktadır (12). Bu nedenle bu çalışmanın sonuçları ameliyat öncesi duş/banyo, tüy temizliği ve deri antisepsisi başlıkları altında tartışımıştır. 


\section{Ameliyat Öncesi Duş/Banyo}

Hastanın ameliyat öncesi duş/banyo yapması ile özellikle cerrahi alandaki bakteriyel yükün azaltılarak CAE riskinin en aza indirimesi amaçlanmaktadır. Ayrıca, ameliyattan önce hastanın banyo yapması hastanın kendisini rahat ve huzurlu hissetmesine de yardımcı olmaktadır (13). Bunun için hastaların ameliyattan önceki gece ya da ameliyat sabahı sabun (antimikrobiyal/antimikrobiyal olmayan) ya da antiseptik ürün ile duş alması/banyo yapması önerilmektedir $(1,11,14)$. Bu çalışmada hemşirelerin az bir kısmı çaış̧ıkları kurumda hastalara ameliyat öncesi rutin olarak duş/banyo yaptırıldığını belirtmişlerdir. Ameliyat öncesi duş/banyo yaptırmayan ve konu ile ilgili kurumlarının uygulamalarını bilmeyen hemşirelerin oranının fazla olması konu ile ilgili eğitim gereksinimini ve hemşirelerin farkındaıı̆ını artırmaya yönelik çalışmalar yapılması gerekliliğini ortaya koymaktadır.

Bu çalışmada ameliyat öncesi duş/banyo uygulamalarında en çok klorheksidin glukonat ve sabun/şampuan kullanıdığı belirlenmiştir. CAE'nin önlenmesine yönelik hazırlanan kılavuzlarda hastalara ameliyat öncesi duş/banyo yaptırma iyi klinik uygulama olarak kabul edilse de uygulamanın zamanlaması ve kullanılacak ajan ile ilgili net öneriler bulunmamaktadır $(1,11,14)$. Ameliyat öncesi duş/banyoda antimikrobiyal özelliği olmayan sabun, povidon iyot ve klorheksidin glukonat gibi çeşitli antimikrobiyal bileşikler kullanılmaktadır. Klorheksidin glukonat içeren bileşikler, rezidüel etkilerinin bulunması ve derideki bakteriyel kolonizasyonu azaltmada en etkili ajan olması nedeniyle kullanımları daha çok önerilmektedir. Ancak CAE gelişiminde anlamlı bir azalma sağlayıp sağlayamadığı konusunda farklı sonuçlar bulunmaktadır $(1,7,10-12,14,15)$. Bu doğrultuda ameliyat öncesi duş/banyo uygulamasının zamanlaması ve kullanılacak ajana ilişkin daha fazla randomize kontrollü çalışmaya gereksinim olduğu düşünülmektedir.

\section{Tüy Temizliği}

Ameliyat bölgesindeki tüylerin temizliği bölgenin görünür olmasını sağlamak, taraf/bölge işaretlemesini ve dikiş atımasını kolaylaştırmak için gerekli görülebilmektedir. Ayrıca tüyler ameliyat sonrası yara pansumanın uygulanmasını ve yapışkan bantların cilde yapışmasına engel olabilmektedir. Tüm bunların yanı sıra, tüylerin ameliyat sırasında uygulanan deri antisepsisini engelleyebileceği için CAE riskini arttırabileceği düşünülmektedir (1,14-17). Tüm bu nedenlerle tüy temizliği geleneksel olarak ameliyat öncesi hasta hazırlığının rutin bir parçası olmuştur. Ancak CAE'larının önlenmesine yönelik yayınlanan güncel kılavuzlar ameliyat bölgesindeki tüylerin gerekli olmadıkça temizlenmesi önerilmemektedir $(1,5,14-17)$. Konu ile ilgili yapılan çalışmalarda tüylerin enfeksiyon için bir risk faktörü olarak görüldüğü ve dünya genelinde ameliyattan önce genellikle temizlendikleri belirtilmektedir (18-20). Bu çalışmada da hastaların çoğunluğunun ameliyat bölgesindeki tüylerinin gerekli olup olmadığı düşünülmeksizin rutin olarak temizlendiği belirlenmiştir. Bu sonuç, cerrahın tercihi ile ilgili bir uygulama olup, geleneksel bakış açısının yaygın olduğunu yansıtmaktadır.

Ameliyat bölgesindeki tüylerin temizliğinde en çok tıraş bıçağı, elektrikli tıraş makinesi (klipper) ve tüy dökücü kremler kullanılmaktadır $(5,21)$. Konu ile ilgili yayınlanan kılavuzlar ve yapılan meta-analizlerde hastanın cildinde mikroskobik travmaya neden olarak CAE riskini artırması nedeniyle tıraş bıçaklarının kullanımı önerilmemektedir (1, $14,17,21,22)$. Deri travmasını en aza indirebilmek için tüy temizliğinde elektrikli tıraş makinelerinin (klipper) kullanımı önerilmektedir (14). Bu çalışmada ameliyathane hemşirelerinin çoğunluğu tüy temizliğinde elektrikli tıraş makinelerini (klipper) kullandıklarını belirtseler de hemşirelerin bir bölümü hala tıraş bıçaklarını kullandıklarını belirtmiştir. $\mathrm{Bu}$ sonucun, sadece hemşirelerin tutumlarından kaynaklanmayacağı, kurumun olanakları ile de ilgili olduğu düşünülmektedir.

Literatürde tüylerin temizlenmesinde kullanılan yöntemin yanında tüylerin temizlenme zamanı ve işlemin yapıldığı yerin cerrahi alan enfeksiyonları açısından risk faktörü olduğu belirtilmektedir. Bununla birlikte CAE önlenmesine yönelik yayınlanan kılavuzlarda tüy temizliğinin zamanlaması ve yerine yönelik kanıt temelli öneri bulunmasa da ameliyata en yakın sürede ve ameliyathanede özel bir odada yapılmasının uygun olacağı belirtilmektedir $(1,5$, $14,16)$. Bu çalışmada da tüy temizliğinin yeri ve zamanlamasına yönelik farklı uygulamaların olduğu saptanmıştır. Uygulamadaki bu farklııkların konu ile ilgili kılavuzlarda kanit temelli uygulamaların net olmamasından ve kurumlardaki fiziksel olanaklardan kaynaklanabileceği düşünülmektedir. Bu sonuçlar tüy temizliğinin zamanlaması ve yerine yönelik çalışmalara gereksinim olduğunu göstermektedir.

\section{Deri Antisepsisi}

Deri antisepsi kalıı florayı mümkün olduğunca azaltmak, geçici florayı ortamdan uzaklaştımak amacıyla ameliyat alanı ve çevresinin antiseptik bir solüsyon ile mekanik olarak temizlenmesidir $(6-8,11,23)$. Deri antisepsisi gerektiğinde insizyonun genişletilmesine, ek bir insizyonun yapılabilmesine ve dren yerleştirilmesine izin verecek şekilde en az $15-20 \mathrm{~cm}$ alanında uygulanmaktadır $(6-8,23)$. Bu çaIş̧mada insizyon alanından ortalama $21.6 \pm 12.2 \mathrm{~cm}$ uzaktaki mesafeye kadar deri antisepsisi uygulandığı belirlenmiştir. Bu doğrultuda çalışmamızda deri antisepsisinin yeterli güvenlik alanı oluşturacak şekilde uygulandığı söylenebilir.

CAE önlenmesine yönelik yayınlanan kılavuzlarda deri antisepsisinde kullanılacak ajana yönelik kanıt temelli öneri bulunmamaktadır (14). Deri antisepsisinde en yaygın kullanılan ajanlar, çok çeşitli bakteri, mantar ve virüslere karşı etkili olan alkol bazlı klorheksidin glukonat ve povidon iyodin çözeltileridir $(11,14,24)$. Bununla birlikte, gelişmekte olan ülkelerde iyodoforlar yaygın olarak kullanılmaktadır 
(14). Bu çalışmada da deri antisepsisinde büyük oranda povidon iyot kullanıldığı saptanmıştır.

Deri antisepsisinin insizyon alanından perifere doğru, dairesel hareketlerle ve steril eldiven ile yapılması önerilmektedir $(6-8,23)$. Bu çalışmada hemşirelerin büyük çoğunluğunun deri antisepsisini insizyon alanından dışarıya doğru ve steril eldiven kullanarak yaptığı belirlenmiştir. Bulgularımız literatüre paralellik göstermektedir.

Kimyasal ve termal yanık oluşumunun önlenmesi için deri antisepsisinde kullanılan antiseptik solüsyonun cerrahi örtüleri ıslatması ve hastanın ya da kullanılan ekipmanın altında birikmesi önlenmelidir $(6-8,11,23)$. Bu çalışmada hemşirelerin çoğunluğunun deri antisepsisinde kullanılan solüsyonun hastanın altında birikmesini önlemek için hastanın her iki tarafına kompres yerleştirdiği belirlenmiştir. Wistrand et al. (24) tarafından yapılan bir çalışmada ameliyathane hemşirelerinin çoğunluğunun deri antisepsisini 25 dakika uyguladıkları ve \%41,1'inin sıklıkla deri antisepsisini uyguladıktan sonra antiseptiğin kurumasını bekledikleri belirlenmiştir. Bu çalışmada da deri antisepsisinin orta-

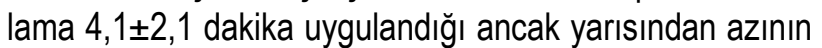
hasta örtülmeden önce antiseptiğin kurumasını bekledikleri belirlenmiştir. Deri antisepsisi uygulama süresi uygun olmasına rağmen, çoğunlukla kuruması için yeterli süre verilmemesinin ameliyat olan hasta sayısının fazla olması ve zaman kaygısı yaşanması ile ilişkili olabileceği düşünülmektedir.

Çalışmalarda iyodofor emdirilmiş ya da emdirilmemiş insizyon örtüleri (drapelerin) kullanımının CAE'yi önlemeye yönelik etkisi olmadığı bildirilmektedir $(1,25)$. Çalışmada hemşirelerin çoğunluğu ameliyat sırasında steril drape kullandıklarını bildirmişlerdir. Bu uygulamanın yalnızca hemşirenin değil cerrahi ekibin ortak kararı olduğu düşünülmektedir. Ancak etkinliğinin olmadığı kanıtlanmasına rağmen uygulamaya devam edilmesinin güncel uygulamaların takibinin yapılmaması nedeniyle olabileceği düşünülebilir. Bu çalışmada, banyo/duşun rutin uygulanma oranının düşük olması, tüy temizliğinin rutin yapılması, tüy temizliğinin çoğunlukla ameliyattan hemen önce elektrikli tıraş makineleri (klipper) ile yapılıyor olmasına rağmen tıraş bıçağının hala kullanıyor olması CAE gelişme riski yönünden önemli bir sonuçtur. Deri antisepsisi uygun antiseptik solüsyon ile (povidon iyot) yeterli alanda, yeterli sürede ve uygun teknik ile yapılmasına rağmen kullanılan antiseptik solüsyonun kurumasının beklenmemesi CAE açısından risk oluşturabilir. Çalışmamızda drape kullanımı da oldukça fazla olup gerekli olmadığı halde kullanıması maliyet açısından önemlidir. Bu sonuçlar doğrultusunda, ameliyathane hemşirelerinin de dahil olduğu tüm ameliyathane ekibinin CAE'yi önleme konusundaki bilgilerinin güncellenmesi gerektiği düşünülmektedir. Bu amaçla güncel kanıt temelli önerileri içeren bakım paketleri, algoritmalar, standartların vb. oluşturulmasının, kanıtların uygulamada kullanımasını kolaylaştırabileceği ve ekip iş birliğini sağlayabileceği düşünülmektedir.

Etik Onam: Çalışma için Kütahya Sağlık Bilimleri Üniversitesi Rektörlügü Girişimsel Olmayan Klinik Araştırmalar Etik Kurulundan onay alındı (19.03.2019 tarih, 2019/04 nolu karar)

\section{Kaynaklar}

1. Berríos-Torres SI, Umscheid CA, Bratzler DW, Leas B, Stone EC, Kelz RR, et al. Centers for Disease Control and Prevention guideline for the prevention of surgical site infection, 2017. JAMA Surg. 2017; 152(8): 784-791.

2. Magill SS, Hellinger W, Cohen J, Kay R, Bailey C, Boland B, et al. Prevalence of healthcare-associated infections in acute care hospitals in Jacksonville, Florida. Infect Control Hosp Epidemiol. 2012; 33(3): 283-291.

3. Bashaw MA., Keister KJ. Perioperative strategies for surgical site infection prevention. AORN Journal. 2019; 109(1): 68-78.

4. Mu Y, Edwards JR, Horan TC, Berrios-Torres SI, Fridkin SK. Improving risk-adjusted measures of surgical site infection for the national healthcare safety network. Infect Control Hosp Epidemiol. 2011; 32(10): 970-986.

5. Aygin D, Marul F. Cerrahi alan enfeksiyonu tanımlarında yenilikler ve ameliyat öncesi tüy temizliğinde güncel uygulamalar. Online Türk Sağık Bilimleri Dergisi. 2016; 1(3):28-36.

6. Rothrock JC, Mc Ewen DR. Alexanders Care of the Patient in Surgery. Fourteen ed. St Louis: Elsevier Mosby, 2011: 95-107.

7. Association of periOperative Registered Nurses (AORN). Preoperative patient skin antisepsis. In: Conner R (ed). Perioperative Standards and Recomended Practices, 2014 Edition. United States of America, 2014:73-88.

8. Kaymakçı Ş. Ameliyathanede asepsinin sağlanması. İçinde: Yavuz van Giersbergen M, Kaymakçı Ş (editörler). Ameliyathane Hemşireliği. Meta Basım Matbaacılık Hizmetleri, İzmir, 2015:423-444.

9. Pronovost $P$, Berenholtz $S$, Needham D. Translating evidence into practice: a model for large scale knowledge translation. BMJ. 2008; 337: 963-965.

10. Kalkan N, Karadağ M. Cerrahi alan enfeksiyonlarını önlemede güncel yaklaşımlar ve hemşirelere yönelik önleme girişimleri algoritması. Gümüşhane Üniversitesi Sağlık Bilimleri Dergisi. 2017; 6(4): 280-289.

11. Álvarez CA, Guevara CE, Valderrama SL, Sefair CF, Cortes JA, Jimenez MF, et al. Practical recommendations for preoperative skin antiseptic. Infectio. 2018; 22(1): 46-54.

12. Candan Dönmez Y. Ameliyat öncesi cilt hazırlığı. Turkiye Klinikleri J Surg Nurs-Special Topics. 2016; 2(2): 11-16.

13.Yavuz van Giersbergen M. Ameliyat öncesi hemşirelik yönetimi. İçinde: Yavuz van Giersbergen M, Kaymakçı Ş (editörler). Ameliyathane Hemşireliği. Meta Basım Matbaacılık Hizmetleri, İzmir, 2015: 273-295. 14. World Health Organization (WHO). Global guidelines for the prevention of surgical site infection WHO, Geneva, 2016. [cited 30 May 2019]. Available from: https://www.who.int/gpsc/ssi-guidelines/en/.

15. l̇yigün E, Ayhan H, Taştan S, Köse G. Kraniyal cerrahide tıraşsız cilt hazırlığının cerrahi alan enfeksiyonu gelişimine etkisi: sistematik inceleme. Journal of Neurological Sciences. 2010; 27(2): 185-196.

16. Uslu Y, Yavuz M. Ameliyat öncesi tüy temizliği: Sistematik inceleme. Ege Üniversitesi Hemşirelik Fakültesi Dergisi. 2015; 31(2): 67-77.

17. Öğce F, Kaymakçı Ş, Çakır Umar D, Candan Dönmez Y, Dolgun E, Turhan Damar $\mathrm{H}$, ve ark. Cerrahi alan enfeksiyonunu önlemede ameliyat öncesi kıl temizliği. 2018. Türk Cerrahi ve Ameliyathane Hemşireleri Derneği. [cited 30 May 2019].

Available from: http://tcahd.org/gorseller/files/K\%C4\%B1|\%20Temizlig\%CC\%86i\%20\%20ic\%CC\%A7in\%20K\%C4\%B1lavuz-

lar\%20ve\%200\%CC\%88neriler-26_04_2018.pdf.

18. Pan A, Ambrosini L, Patroni A, Soavi L, Signorini L, Carosi G, et al. 
Adherence to surgical site infection guidelines in Italian cardiac surgery units. Infection. 2009; 37: 148-152.

19. Husted H, Gromov K, Malchau H, Freiberg A, Gebuhr P, Troelsen $A$, et al. Traditions and myths in hip and knee arthroplasty. Acta Orthopaedica. 2014; 85: 548-555.

20. Shi D, Yao Y, Yu W. Comparison of preoperative hair removal methods for the reduction of surgical site infections: a meta-analysis. Journal of Clinical Nursing. 2016; 26:2907-2914.

21. Tanner J, Norrie P, Melen K. Preoperative hair removal to reduce surgical site infection. Cochrane Database Syst Rev. 2011; (11): CD004122.

22. Lefebvre A, Saliou P, Lucet JC, Mimoz O, Keita-Perse O, Grandbastien B, et al. Preoperative hair removal and surgical site infections: network meta-analysis of randomized controlled trials. Journal of Hospital Infection. 2015; 91(2): 100-108.

23. Özbayır T. Ameliyat dönemi bakımı. İçinde: Karadakovan A, Eti Aslan $F$ (editörler) Dahili ve Cerrahi Hastalıklarda Bakım. 4. Baskı, Nobel Tıp Kitabevi, Adana, 2017: 241-279.

24. Wistrand C, Falk-Brynhildsen K, Nilsson U. National survey of operating room nurses' aseptic techniques and interventions for patient preparation to reduce surgical site infections. Surgical Infections. 2018; 19(4): 438-445.

25. Webster J, Alghamdi A. Use of plastic adhesive drapes during surgery for preventing surgical site infection. Cochrane Database Syst Rev. 2015; 22(4): CD006353. 